\title{
PERENCANAAN PENJUALAN UNTUK MENCAPAI LABA MINIMUM \\ CV. JAWA INDAH DENGAN MENGGUNAKAN BREAK EVENT POINT
}

\author{
Oleh : \\ Ignatiar Keyko Diana Mewoh \\ David P.E Saerang \\ Victorina Tirajoh \\ Fakultas Ekonomi dan Bisnis, Jurusan Akuntansi \\ Universitas Sam Ratulangi \\ email : keykodiana@yahoo.com
}

\begin{abstract}
ABSTRAK
Kenaikan harga kedelai di tahun 2013 mengerdilkan industri tahu-tempe untuk berproduksi, akibatnya muncul seruan untuk mogok produksi ini dikarenakan perusahaan mengalami kerugian akibat dampak kenaikan harga kedelai. Hal ini tentu sangat disesalkan karena mengingat tahu dan tempe merupakan makan khas negara Indonesia. Tujuan dari penelitian ini adalah untuk mengetahui jumlah penjualan yang harus dipertahankan,penjualan yang minimal harus dicapai perusahaan serta memprediksi akibat dari perubahan elemen penentu break event point. Jenis penelitian ini yaitu deskriptif kuantitatif dengan menggunakan metode studi kasus pada CV. Jawa Indah yang terletak di desa Tumpaan I, Kabupaten Minahasa Selatan dan variabel yang diteliti tidak dikenai suatu tindakan manipulasi. Hasil penelitian menunjukkan bahwa penjualan yang harus dipertahankan oleh perusahaan adalah produk tahu dengan penjualan minimal Rp. 608.766.084 di tahun 2013 selain itu perubahan elemen penentu break even berpengaruh terhadap perencanaan laba yaitu bila harga jual naik mengakibatkan break even point naik dan laba turun.
\end{abstract}

Kata kunci : break event point, perencanaan laba

\section{A B S T R A C T}

Rise in soybean prices in 2013 dwarfed the industry for producing tofu, tempeh, consequently emerged a call for strike is due to production losses due to the impact of rising soybean prices. This is very regrettable because remember eating tofu and tempeh are typical of Indonesia. The purpose of this study was to determine the amount of sales that must be maintained, at least have achieved sales companies as well as predict the effect of changes in critical elements of break-even point. This type of research is descriptive quantitative case study using the CV. Java Indah village of Tumpaan I, South Minahasa regency and the variables studied are not subject to an act of manipulation. The results showed that the sales should be maintained by the company is selling the product out with a minimum of Rp. 608.766.084 in the year 2013 than it changes the defining element of planning the break-even effect on the profit when selling price rise resulted in the break-even point and profit climbed down.

Keywords : break event point, profit planning 


\section{Latar Belakang}

\section{PENDAHULUAN}

Tujuan sebuah perusahaan adalah untuk memperoleh keuntungan atau laba yang dapat di pergunakan untuk kelangsungan hidup. Mendapatkan keuntungan atau laba dan besar kecilnya laba sering menjadi ukuran kesuksesan suatu manajemen. Hal tersebut didukung oleh kemampuan manajemen di dalam melihat kemungkinan dan kesempatan dimasa yang akan datang.

Manajemen dituntut untuk menghasilkan keputusan-keputusan yang menunjang terhadap pencapaian tujuan perusahaan serta mempercepat perkembangan perusahaan. Manajemen memerlukan suatu perencanaan untuk perusahaan dalam mencapai tujuannya tersebut. Ukuran yang sering dipakai untuk menilai sukses tidaknya manajemen suatu perusahaan adalah dari laba yang diperoleh perusahaan.

Analisis break even menyajikan informasi hubungan biaya, volume dan laba kepada manajemen. Sehingga memudahkan dalam menganalisis faktor yang mempengaruhi pencapaian laba perusahaan dimasa yang akan datang. CV. Jawa Indah adalah perusahaan yang melakukan berbagai upaya ke arah peningkatan volume penjualan dengan tujuan untuk meningkatkan keuntungan.

\section{Tujuan Penelitian}

Tujuan penelitian ini adalah:

1. Mengetahui penjualan yang harus dipertahankan agar perusahaan tidak mengalami kerugian tahun 2013.

2. Mengetahui jumlah penjualan minimal yang harus dicapai pada jumlah laba yang direncanakan CV.Jawa Indah pada tahun 2013

3. Mengetahui akibat dari perubahan elemen penentu break even point terhadap perencanaan laba pada CV.Jawa Indah tahun 2013

\section{Akuntansi Manajeman}

\section{TINJAUAN PUSTAKA}

Akuntansi Manajemen atau Akuntansi Manajerial adalah sistem akuntansi yang berkaitan dengan ketentuan dan penggunaan informasi akuntansi untuk manajer atau manajemen dalam suatu organisasi dan untuk memberikan dasar kepada manajemen untuk membuat keputusan bisnis yang akan memungkinkan manajemen akan lebih siap dalam pengelolaan dan melakukan fungsi kontrol.

\section{Akuntansi Biaya}

Akuntansi biaya adalah salah satu cabang akuntansi yang merupakan alat bagi manajemen untuk memonitor dan merekam transaksi biaya secara sistematis, serta menyajikan informasi biaya dalam bentuk laporan biaya.

\section{Perencanaan Laba}

Perencanaan laba dapat didefinisikan sebagai himpunan langkah-langkah yang diambil oleh perusahaan untuk mencapai tingkat keuntungan yang diinginkan.

\section{Definisi dan Pengertian Break Event Point}

Break event point adalah suatu keadaan dimana dalam suatu operasi perusahaan tidak mendapat untung maupun rugi/ impas (penghasilan = total biaya). Berikut adalah pengertian - pengertian Break Even Point menurut para ahli.

1. Munawir (2002), menyatakan titik break even point atau titik pulang pokok dapat diartikan sebagai suatu keadaan dimana dalam operasinya perusahaan tidak memperoleh laba dan tidak menderita rugi (total penghasilan $=$ Total biaya) .

2. Harahap (2004) Menyatakan Break even point berarti suatu keadaan dimana perusahaan tidak mengalami laba dan juga tidak mengalami rugi artinya seluruh biaya yang dikeluarkan untuk kegiatan produksi ini dapat ditutupi oleh penghasilan penjualan. Total biaya (biaya tetap dan biaya variabel) sama dengan total penjualan sehingga tidak ada laba tidak ada rugi. ( Zone,2009)

\section{Manfaat dan Kegunaan Break Event Point}

Analisa break even point sangat penting bagi pimpinan perusahaan untuk mengetahui pada tingkat produksi berapa jumlah biaya akan sama dengan jumlah penjualan atau dengan kata lain dengan mengetahui 
break even point kita akan mengetahui hubungan antara penjualan, produksi, harga jual, biaya, rugi atau laba, sehingga memudahkan bagi pimpinan untuk mengambil kebijaksanaan.

Harahap (2004) menyatakan dalam analisa laporan keuangan kita dapat menggunakan rumus break even point untuk mengetahui :

1. Hubungan antara penjualan biaya dan laba.

2. Untuk mengetahui struktur biaya tetap dan biaya variabel.

3. Untuk mengetahui kemampuan perusahaan dalam menekan biaya dan batas dimana perusahaan tidak mengalami laba dan rugi.

4. Untuk mengetahui hubungan antara cost, volume, harga dan laba.

\section{Jenis Biaya Berdasarkan Break Even Point (Titik Impas)}

Hongren, et al (2008) menyatakan biaya yang dikeluarkan perusahaan dapat dibedakan sebagai berikut.

1. Variabel Cost (biaya Variabel)

Variabel cost merupakan jenis biaya yang selalu berubah sesuai dengan perubahan volume penjualan, dimana perubahannya tercermin dalam biaya variabel total.

2. Fixed Cost (biaya tetap)

Fixed cost merupakan jenis biaya yang selalu tetap dan tidak terpengaruh oleh volume penjualan melainkan dihubungkan dengan waktu (function of time) sehingga jenis biaya ini akan konstan selama periode tertentu.

3. Semi Variabel Cost

Semi variabel cost merupakan jenis biaya yang sebagian variabel dan sebagian tetap, yang kadangkadang disebut dengan semi fixed cost.

\section{Dasar Asumsi Analisis Break Event Point}

Analisis break even mempunyai beberapa asumsi yang tercermin dalam anggaran perusahaan masa yang akan datang. Dasar asumsi yang mendasari analisis break even menurut Halim dan Supomo (2005:58) sebagai berikut.

a. Harga jual per unit tidak berubah-ubah pada berbagai volume penjualan.

b. Perusahaan berproduksi pada jarak kapasitas yang secara relatif konstan.

c. Biaya dapat dipisahkan menjadi biaya tetap dan biaya variabel. Biaya tetap jumlahnya tidak berubah dalam jarak kapasitas tertentu, sedangkan biaya variabel berubah secara proporsional dengan perubahan volume kegiatan perusahaan.

d. Jumlah perubahan persedaiaan awal dan persediaan akhir tidak berarti.

e. Jika perusahaan menjual lebih dari satu macam produk, komposisi produk yang dijual dianggap tidak berubah.

\section{Perhitungan Break Event Point (BEP)}

Break even point (BEP) dapat dihitung menggunakan metode persamaan dan metode marjin kontribusi.

Kedua metode tersebut memberikan hasil yang sama .

a. Pendekatan Persamaan

Laba $=$ Penjualan $-($ Biaya Variabel + Biaya Tetap $)$

Penjualan = Biaya Variabel + Biaya Tetap + Laba

b. Pendekatan Margin Kontribusi.

(Garrison, 2006 : 334)

Total Biaya Tetap

Impas Rupiah $=$ $1-\quad$ Total BV

Total harga jual

Impas Rupiah $=$

Total Biaya Tetap

Impas Unit =

$$
\text { Rasio Margin Kontribusi }
$$

Total Biaya Tetap

Harga Jual per Unit - Biaya Variabel per Unit 


\section{Penggolongan Biaya Atas Dasar Tingkah Laku \\ 1. Biaya Tetap}

Carter dan Usry (2006:58) "Biaya tetap adalah sebagai biaya yang secara total tidak berubah saat aktivitas bisnis meningkat atau menurun". Jika dalam semua aktivitas bisnis menurun sampai ke titik nol, perusahaan akan melikuidasi dan menghindari semua biaya

2. Biaya Variabel

Carter dan Usry (2006:59) "Biaya variabel adalah sebagai biaya yang secara total meningkat secara proporsional terhadap peningkatan dalam aktivitas dan menurun secara proposional terhadap penurunan dalam aktivitas".

3. Biaya Semi Variabel

Biaya semi variabel adalah biaya yang memiliki unsur tetap dan variabel di dalamnya. (Mulyadi,2012:469).Unsur biaya tetap merupakan jumlah biaya minimum untuk penyediaan jasa, sedangkan unsur biaya variable merupakan bagian dari biaya semi variabel yang dipengaruhi oleh perubahan volume kegiatan.

\section{Analisis Biaya, Volume dan Laba}

Analisis hubungan biaya, volume dan laba terhadap faktor-faktor yang mempengaruhi laba dapat dibuat dengan menggunakan persamaan biaya, volume dan laba sebagai berikut.

Total Penghasilan $=$ Total Biaya Tetap + Total Biaya Variabel + Laba

$P x=a+b x+c$

\section{Penelitian Terdahulu}

Tabel 1. Penelitian Terdahulu

\begin{tabular}{|c|c|c|c|c|c|c|}
\hline $\begin{array}{c}\text { Nama } \\
\text { Peneliti/ } \\
\text { Tahun }\end{array}$ & Judul & Tujuan & $\begin{array}{c}\text { Metode } \\
\text { Penelitian }\end{array}$ & Hasil Penelitian & Persamaan & Perbedaan \\
\hline Eri / 2007 & $\begin{array}{l}\text { "Analisis } \\
\text { Cost,Volume,Pr } \\
\text { ofit sebagai Alat } \\
\text { Bantu } \\
\text { Perencanaan } \\
\text { Laba Pada } \\
\text { Perusahaan } \\
\text { Tempe Murni } \\
\text { Pedro di } \\
\text { Yogyakarta" }\end{array}$ & $\begin{array}{l}\text { "Untuk } \\
\text { mengetahui } \\
\text { pengaruh } \\
\text { perubahan } \\
\text { setiap elemen } \\
\text { penentu break } \\
\text { event point" }\end{array}$ & $\begin{array}{l}\text { Deskriptif } \\
\text { kualitatif }\end{array}$ & $\begin{array}{l}\text { Perubahan laba } \\
\text { dihitung } \\
\text { menggunakan } \\
\text { analisis tingkat } \\
\text { operating laverage } \\
\text { yaitu saat volume } \\
\text { penjualan } \\
\text { bertambah 5\% } \\
\text { maka laba akan } \\
\text { meningkat sebesar } \\
5,70 \% \\
\text { yaitu sebesar Rp } \\
\text { 9.476.136,00 } \\
\text { sehingga laba } \\
\text { menjadi Rp } \\
\text { 175.724.136 }\end{array}$ & $\begin{array}{l}\text { Memiliki tujuan } \\
\text { yang sama salah } \\
\text { satunya yaitu } \\
\text { untuk } \\
\text { mengetahui } \\
\text { pengaruh } \\
\text { perubahan } \\
\text { elemen break } \\
\text { even terhadap } \\
\text { perencanaan laba } \\
\text { perusahaan. }\end{array}$ & \begin{tabular}{lr} 
Metode & \multicolumn{2}{c}{ sebelumnya } \\
menggunakan & metode \\
deskriptif & kualitatif \\
sedangkan & pada \\
penelitian & ini \\
menggunakan metode & meskriptif kuantitatif
\end{tabular} \\
\hline $\begin{array}{l}\text { Khasanah/ } \\
2007\end{array}$ & $\begin{array}{l}\text { "Analisis Break } \\
\text { Even untuk } \\
\text { Merencanakan } \\
\text { Laba pada PT. } \\
\text { Tambi } \\
\text { Wonosobo" }\end{array}$ & $\begin{array}{l}\text { Membanding } \\
\text { kan perolehan } \\
\text { laba,bila } \\
\text { elemen BEP } \\
\text { berubah }\end{array}$ & $\begin{array}{l}\text { Deskriptif } \\
\text { kuantitatif }\end{array}$ & $\begin{array}{l}\text { Perubahan elemen } \\
\text { penentu break } \\
\text { even berpengaruh } \\
\text { terhadap } \\
\text { perencanaan } \\
\text { Laba. }\end{array}$ & $\begin{array}{l}\text { Analisis data } \\
\text { menggunakan } \\
\text { rumus break } \\
\text { even dan margin } \\
\text { of safety. }\end{array}$ & $\begin{array}{l}\text { Penelitian sebelumnya } \\
\text { menggunakan data } \\
\text { sekunder, untuk } \\
\text { penelitian kali ini } \\
\text { adalah data primer }\end{array}$ \\
\hline
\end{tabular}

\section{Jenis Penelitian}

\section{METODE PENELITIAN}

Penelitian ini menggunakan desain penelitian studi kasus pada perusahaan. Metode pada penelitian ini menggunakan pendekatan expost facto karena variabel yang diteliti tidak dikenai suatu tindakan, perlakuan atau manipulasi, melainkan hanya meneliti dan mengungkapkan faktor-faktor yang diteliti berdasarkan keadaan yang sudah ada (Kuncoro,2009:89).

\section{Tempat dan Waktu Penelitian}

Penelitian ini dilaksanakan di CV Jawa Indah yang berlokasi di Desa Tumpaan Satu Kecamatan Tumpaan, Kabupaten Minahasa Selatan; Sulawesi Utara. Pemilihan lokasi ini dilakukan secara sengaja karena 
CV Jawa Indah bergerak di bidang manufaktur yaitu memproduksi dan memasarkan tahu sehingga cocok sebagai tempat penelitian mengenai harga pokok produksi serta adanya kesediaan dari pemilik untuk memberikan data yang dibutuhkan dalam melakukan penelitian. Penelitian ini dilakukan pada Mei 2013-Juni 2013.

\section{Prosedur Penelitian}

Adapun prosedur penelitian kami kali ini yaitu.

1. Studi pendahuluan

2. Menentukan Permasalahan

3. Penelitian; Observasi, Wawancara dan Dokumentasi

4. Analisa data

5. Hasil dan Kesimpulan

\section{Metode Pengumpulan Data}

Untuk mendapatkan data yang diperlukan dalam penulisan ini, maka metode penelitian yang digunakan sebagai berikut.

Jenis Data yang diperlukan dalam penelitian ini adalah.

1. Data Kualitatif terdiri dari.

1) Sejarah Perusahaan

2) Kegiatan Perusahaan

3) Tugas masing-masing bagian dalam perusahaan.

2. Data Kuantitatif yaitu laporan penjualan

\section{Sumber Data}

Yang menjadi sumber data dalam penelitian ini adalah. Data Primer Data yang di peroleh langsung dari perusahaan CV. Jawa Indah yaitu.

1) Sejarah Perusahaan

2) Kegiatan Usaha Perusahaan

3) Tugas masing-masing bagian dalam perusahaan

4) Laporan penjualan

\section{Teknik Pengumpulan Data}

Metode yang digunakan dalam pengumpulan data yaitu :

1. Wawancara : Peneliti melakukan wawancara secara langsung dengan pihak yang terkait yaitu dengan pemilik dan karyawan CV Jawa Indah dengan mengajukan pertanyaan-pertanyaan mengenai perencanaan laba pada CV Jawa Indah

2. Pengamatan (Observasi) secara langsung terhadap aktivitas produksi tahu. Penulis mengamati bagaimana proses produksi CV Jawa Indah dan mengidentifikasi biaya-biaya yang digunakan selama proses produksi.

3. Dokumentasi; Dokumentasi yaitu teknik pengumpulan data yang dilakukan dengan jalan mengadakan pencatatan, pengumpulan bahan-bahan tertulis, yang mempunyai keterkaitan dengan permasalahan yang tengah peneliti amati.

\section{Metode Analisis Data}

Metode analisis data yang digunakan dalam penelitian ini yaitu.

1. Untuk menentukan besarnya tingkat penjualan dalam keadaan break even dengan rumus:

Impas rupiah $=$

Impas unit $=$
Total Biaya Tetap

\begin{tabular}{c}
$1-$ Total BV \\
\cline { 2 - 2 } Total harga jual
\end{tabular}

Atau

Total Biaya Tetap

Harga Jual per Unit - Biaya Variabel per Unit 
$\mathrm{MS}=$

$\% \mathrm{MS}=$

$\overline{\mathrm{SB}}$

3. Untuk membuat keputusan yang berhubungan dengan perubahan harga jual, biaya dan volume terhadap laba perusahaan Contribution Margin = Penjualan - Biaya Variabel. Untuk mengetahui contribution margin sebagai akibat perubahan setiap rupiah penjualan

Rasio $\mathrm{CM}=\frac{\mathrm{CM}}{\text { Penjualan }}$

4. Untuk menentukan penjualan minimal pada laba yang telah ditetapkan

Penjualan Minimal $=\frac{\text { Biaya tetap }+ \text { Laba yang direncanakan }}{\text { Rasio Contribution Margin }}$

5. Untuk memisahkan biaya tetap dan variable, pada biaya semi variable menggunakan metode kuadrat terkecil

$y=a+b x$

$\mathrm{b}=$

$\mathrm{a}=\frac{{ }_{\mathrm{n}} \Sigma_{\mathrm{x}}^{2}-(\Sigma \mathrm{x})}{\mathrm{n}-\mathrm{b} \Sigma \mathrm{x}}$

\section{Gambaran Umum Objek Penelitian}

\section{HASIL PENELITIAN DAN PEMBAHASAN}

Objek penelitian kali ini adalah perusahaan manufaktur yang bergerak dibidang usaha tahu dan tempe milik Bapak Iman, yang berlokasi di desa Tumpaan Satu, Kec. Tumpaan Kabupaten Minahasa Selatan, Sulawesi Utara.

\section{Hasil Penelitian}

Laba yang diinginkan dapat diperoleh jika manajer perusahaan dapat membuat perencanaan secara terpadu atas semua aktivitas yang sedang maupun akan dilakukan dalam upaya mencapai laba yang diharapkan. Dalam perencanaan maupun realisasinya manajer dapat memperbesar laba.

Laba merupakan tujuan utama dari perusahaan karena laba merupakan selisih antara pendapatan yang diterima (dari hasil penjualan) dengan biaya yang dikeluarkan, maka perencanaan laba dipengaruhi oleh perencanaan penjualan dan perencanaan biaya.

CV. Jawa Indah tidak mengklafikasikan biaya tetap dan biaya variabel. Oleh karena itu, penulis terlebih dahulu mengklafikasikan biaya tetap dan biaya variabelnya. Berikut ini adalah tabel klafikasi biaya tetap dan biaya variabel. 
Tabel 2. Klasifikasi Biaya Tetap dan Biaya Variabel

\begin{tabular}{|ll|l|}
\hline \multicolumn{1}{|c|}{ Jenis Biaya } & \multicolumn{1}{c|}{ Sifat Biaya } \\
\hline a. & Biaya Produksi & Biaya Variabel \\
1. & Biaya Bahan Baku & Biaya Variabel \\
2. & Biaya Tenaga Kerja Langsung & Biaya Variabel \\
3. & Biaya overhead pabrik & Semi Variabel \\
a) & Bahan Penolong & Semi Variabel \\
b) & Biaya Listrik & Biaya Variabel \\
c) & Biaya reparasi \& pemeliharaan & Biaya Tetap \\
d) & BBM genset & \\
e) & Depresiasi & Biaya Tetap \\
\hline b. & Biaya Non Produksi & Biaya Tetap \\
1. & Biaya administrasi \& umum & Semi Variabel \\
a) & Biaya Gaji & \\
b) & Biaya Telepon & Biaya Pemasaran \\
2. & Biaya Pengiriman & \\
a) &
\end{tabular}

\section{Pembahasan}

Rencana laporan laba dapat dihitung dengan menggunakan metode kontrubusi margin setelah data anggaran penjualan diketahui.

\section{Ratio Contribution Margin (RCM)}

Rasio Contribution Margin (RCM) sangat penting dalam menentukan kebijakan bisnis, karena RCM dapat menunjukan bagaimana contrubution margin akan dipengaruhi oleh total penjualan. Untuk mengetahui RCM pada tahun 2011, maka dapat dihitung seperti berikut.

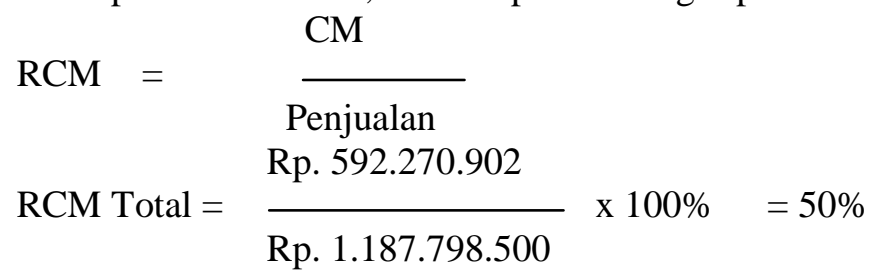

Tahun 2011 CV. Jawa Indah memiliki Ratio contribution margin sebesar 50\%, ini berarti CV. Jawa Indah merencanakan peingkatan penjualan pada tahun 2011 sebesar Rp. 1.187.798.500, selain itu manajemen dapat menentukan contribution margin sebesar Rp. 592.270.902 dengan perolehan laba sebesar Rp. 342.225.123. Ratio Contribution Margin (RCM) untuk tahun 2012 dapat dihitung sebagai berikut.

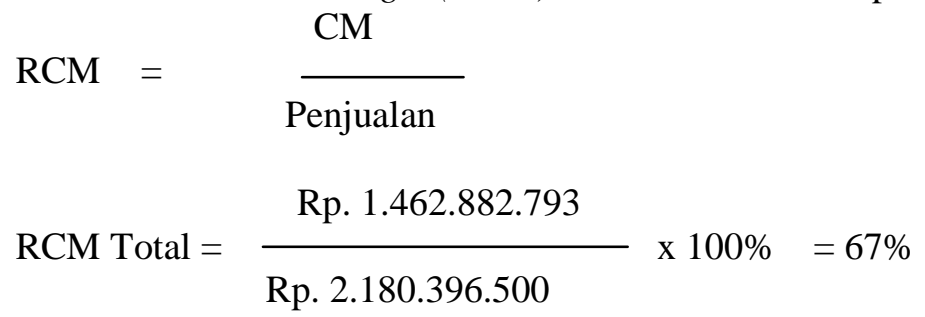

Tahun 2012 CV. Jawa Indah memperoleh Ratio Contribution Margin (RCM) 67\% dengan rencana peningkatan penjualan sebesar Rp. 2.180.396.500 dengan contribution margin yang direncanakan manajemen adalah sebesar Rp. 1.462.882.793 dengan laba Rp. 1.109.821.293.

Ratio Contribution Margin (RCM) untuk tahun 2013 dapat dihitung sebagai berikut.

\section{$\mathrm{CM}$}

$\mathrm{RCM}=$

Penjualan

RCM Total $=\frac{}{\text { Rp. } 1.859 .287 .500} \times 100 \%=57 \%$ 
Tahun 2013 Ratio Contribution Margin (RCM) yang diperoleh adalah sebesar 57\% dengan total perencanaan penjualan sebesar Rp. 1.859.287.500 dengan demikian manajemen dapat menentukan contribution margin sebesar Rp. 1.055.368.460 dan perolehan laba Rp. 861.514.030.

Break Event Point (BEP)

a. Break Event Point (BEP) total tahun 2011 adalah.

$$
\begin{aligned}
& \mathrm{BEP}=\quad \frac{\text { Biaya Tetap }}{\mathrm{RCM}} \\
& \text { BEP Total }=\quad \frac{\mathrm{Rp} .250 .045 .734}{50 \%}=\text { Rp. 500.091.468 }
\end{aligned}
$$

b. Break Event Point (BEP) total tahun 2012 adalah sebagai berikut.

$$
\begin{aligned}
& \mathrm{BEP}=\frac{\text { Biaya Tetap }}{\mathrm{RCM}} \\
& \text { Rp. 353.061.500 } \\
& \text { BEP Total }=\frac{67 \%}{67 \%}=\text { Rp. 526.957.462 }
\end{aligned}
$$

c. Break Event Point (BEP) total tahun 2013 adalah sebagai berikut.

$$
\mathrm{BEP}=
$$$$
\text { Biaya Tetap }
$$

$$
\begin{array}{ll}
\mathrm{BEP}= & \mathrm{RCM} \\
\text { BEP Total } & =\frac{\text { Rp. 193.854.430 }}{57 \%}=\text { Rp. 340.095.491 }
\end{array}
$$

Break Event Point (BEP) menunjukan penjualan perusahaan yang tidak mengalami laba atau rugi. Pada tahun 2011 BEP yang diperoleh CV. Jawa Indah adalah sebesar Rp. 500.091.468. Sedangkan perhitungan BEP masing-masing produk yaitu untuk tahu sebesar Rp. 296.350.498 sedangkan tempe BEP nya yaitu sebesar Rp. 219.552.353. Analisis tersebut menunjukan bahwa lebih baik CV. Jawa Indah memperbanyak produksi tempe, karena BEP tempe lebih sedikit dibandingkan dengan tahu.

Tahun 2012 BEP total yang diperoleh perusahaan adalah Rp. 526.957.462. Sedangkan untuk masingmasing produk, BEP yang dihitung yaitu untuk tahu BEP sebesar Rp. 308.228.293 dan untuk tempe BEP sebesar Rp. 226.968.107. Analisis ini menunjukan bahwa lebih baik CV. Jawa Indah lebih banyak meproduksi tempe karena BEP dari tempe lebih sedikit dibandingkan dengan tahu.

BEP yang diperoleh CV. Jawa Indah pada tahun 2013 adalah sebesar Rp. 340.095 .491 dan untuk masingmasing produk BEP yang diperoleh yaitu untuk tahu sebesar Rp. 155.670.981 dan untuk tempe sebesar Rp. 207.071.777. Berdasarkan analisi BEP dari masing-masing produk, lebih baik CV. Jawa Indah memproduksi lebih banyak tahu karena BEP tahu lebih sedikit dibandingkan BEP dari produk tempe.

\section{Penentuan Penjualan Minimal}

Menentukan target keuntungan atau profit margin adalah salah satu perencanaan yang harus dilakukan suatu perusahaan. Hal yang sama juga harus dilakukan CV. Jawa Indah yaitu merencanakan keuntungan yang harus dicapai dimasa depan. CV. Jawa Indah dalam usahanya ini,menargetkan profit margin sebesar $25 \%$.

Dengan target keuntungan 25\% di tahun 2011 dapat kita hitung seperti berikut.

$$
\begin{aligned}
& \text { Penjualan Minimal }=\frac{}{\text { Rasio Contribution Margin (awal) }} \\
& \text { Penjualan Minimal }=\mathrm{X} \\
& \mathrm{X} \quad=\frac{250.045 .734+25 \%}{} \\
& 50 \% \\
& 50 \% \mathrm{x}=\text { Rp. } 250.045 .734+25 \% \\
& 50 \%-25 \% \mathrm{x}=\text { Rp. } 250.045 .734 \\
& 25 \% \mathrm{x}=\text { Rp. 250.045.734 }
\end{aligned}
$$




$$
\mathrm{X}=\text { Rp. 1.000.182.936 }
$$

Keuntungan 25\% ditahun 2011 dapat diperoleh dari penjualan, oleh karena itu perusahaan harus dapat menjual dan memproduksi produk sebesar Rp. 1.000.182.936.

Tahun 2012 perusahaan menetapkan target keuntungan sebesar 20\%, target keuntungan $20 \%$ dapat dihitung seperti berikut ini.

$$
\begin{aligned}
\text { Penjualan Minimal } & =\frac{\text { Biaya Tetap }+ \text { Laba yang direncankan }}{\text { Rasio Contribution Margin (awal) }} \\
\text { Penjualan Minimal } & =\mathrm{X} \\
\mathrm{X} & =\frac{\text { Rp. } 353.061 .500+20 \%}{67 \%} \\
67 \% \mathrm{x} & =\text { Rp. } 353.061 .500+20 \% \\
67 \%-20 \% \mathrm{x} & =\text { Rp. } 353.061 .500 \\
47 \% \mathrm{x} & =\text { Rp. } 353.061 .500 \\
\mathrm{X} & =\text { Rp. } 751.194 .680
\end{aligned}
$$

Keuntungan 20\% dapat diperoleh ditahun 2012 dari penjualan, oleh karena itu perusahaan harus dapat menjual dan memproduksi produk sebesar Rp. 751.194.680.

Tahun 2013 perusahaan menetapkan target keuntungan sebesar 15\% karena mengingat tahun 2013 harga bahan baku tiba-tiba melonjak sangat drastis. Target keuntungan 15\% dapat dihitung seperti berikut ini.

$$
\begin{aligned}
& \begin{array}{ll}
\text { Penjualan Minimal } & =\frac{\text { Rasio Contribution Margin (awal) }}{\text { Penjualan Minimal }}=\mathrm{X}^{\text {Rat }}
\end{array} \\
& \mathrm{X} \quad=\text { Rp. } 193.854 .430+15 \% \\
& 57 \% \\
& 57 \% \mathrm{x}=\text { Rp. } 193.854 .430+15 \% \\
& 57 \%-15 \% \mathrm{x}=\text { Rp. } 193.854 .430 \\
& 42 \% \mathrm{x}=\text { Rp. } 193.854 .430 \\
& \mathrm{X} \quad=\text { Rp. 461.558.166 }
\end{aligned}
$$

Keuntungan 15\% dapat diperoleh ditahun 2013 dari penjualan, oleh karena itu perusahaan harus dapat menjual dan memproduksi produk sebesar Rp. 461.558.166.

\section{Proyeksi BEP Untuk tahun 2014}

\section{Gambar 1}

Sales Cost

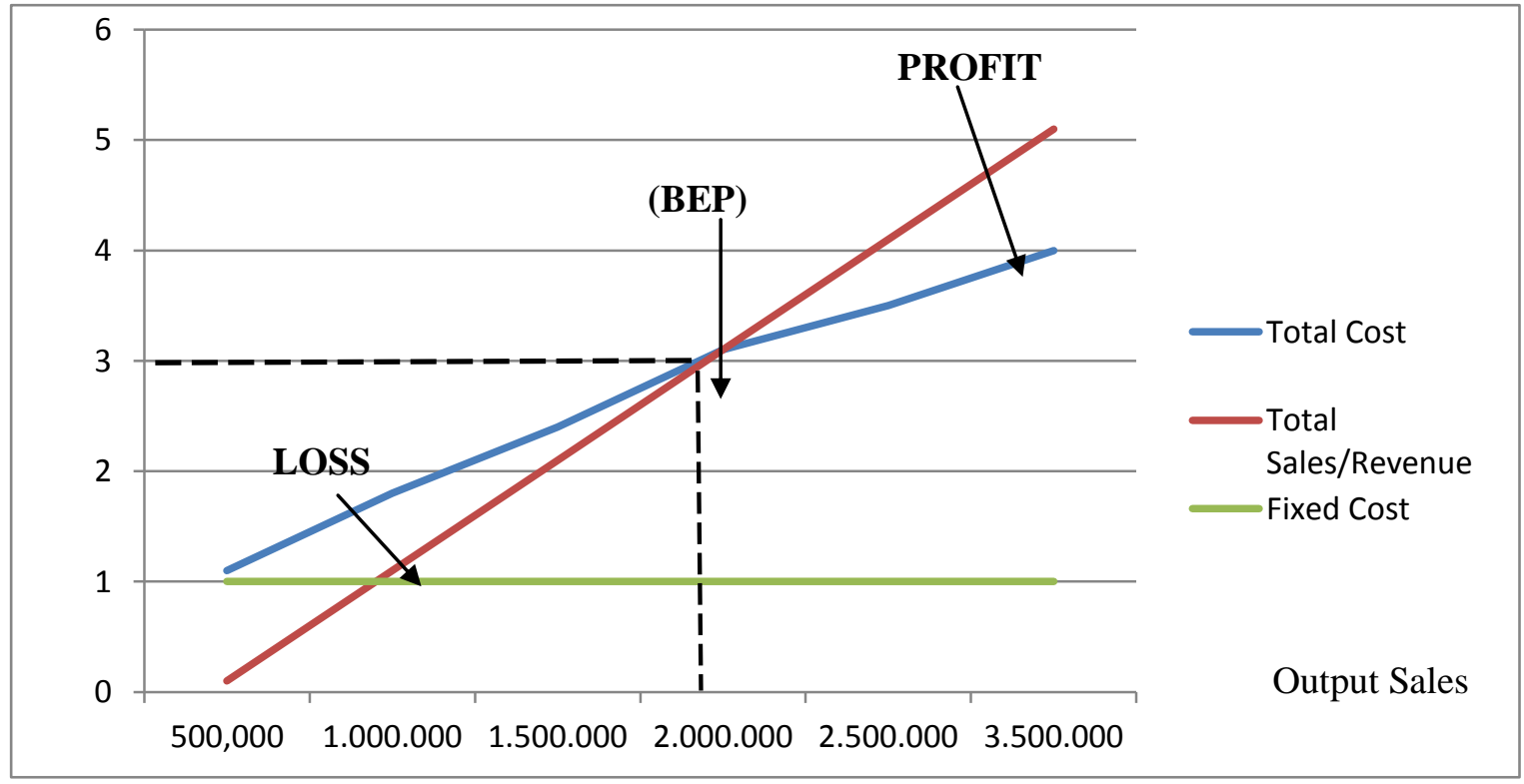

Skala 1:100.000.000 
Dari hasil grafik di atas, CV. Jawa Indah akan memperoleh profit yang diinginkan apabila perusahaan mampu menjual produk lebih dari 2.000 .000 potong atau dengan perolehan laba minimal Rp. 300.000.000 selama tahun 2014 mendatang.

\section{Kesimpulan}

\section{PENUTUP}

Hasil Penelitian dapat disimpulkan bahwa penjualan produk yang harus dipertahankan oleh CV. Jawa Indah adalah produk tahu. Hal ini dikarenakan produk tahu merupakan produk yang paling banyak memberikan kontribusi dan perolehan laba yang besar pada perusahaan. Apabila perusahaan ingin memperoleh laba yang sesuai dengan target, perusahaan harus memperoleh laba penjualan minimal Rp. 1.000.182.936 pada tahun 2011, Rp. 751.194.680 pada tahun 2012 dan Rp.461.558.166 pada tahun 2013. Apabila komposisi penjualan produk berubah dari semula, maka komposisi contribution margin pun ikut berubah. Hal ini akan menyebabkan BEP berubah total dan berdampak besar pada profit perusahaan

\section{Saran}

Saran penelitian ini adalah :

1. Apabila ingin merencanakan laba dengan menggunakan analisis break event point sebaiknya perusahaan memisahkan biaya tetap, biaya variabel dan biaya semi variabel. Dan khusus untuk biaya semi variabel perusahaan harus mengubahnya menjadi biaya tetap dan biaya variabel.

2. Melihat perkembangan yang terjadi pada CV. Jawa Indah dalam melakukan produksi tahu serta dukungan fasilitas yang ada, sebaiknya CV. Jawa Indah lebih meningkatkan produksinya dan melakukan gebrakan baru, misalnya melakukan inovasi pada produk tahu dengan menambah satu jenis produk tahu yakni tahu kuning mengingat produk tahu lah yang banyak diminati konsumen dan mengurangi produksi tempe.

3. Kemampuan yang dimiliki perusahaan dalam memproduksi produk cukup tinggi, hal ini menjadi nilai plus perusahaan dan memungkinkan perusahaan untuk menaikan jumlah produksi dan memperluas distribusi produk,mengingat lokasi tempat perusahaan berdiri merupakan lokasi yang memiliki jumlah penduduk yang cukup besar apalagi sejauh ini perusahaan belum terlalu banyak pesaingnya

\section{DAFTAR PUSTAKA}

Carter, William. K., Usry, Milton F. 2006. Akuntansi Biaya. Edisi Ketigabelas. Buku Satu. Salemba Empat. Jakarta.

Eri, Oktavianti W. 2007. Analisis Cost, Volume, Profit sebagai Alat Perencanaan Laba pada Perusahaan Tempe Murni Pedro di Yogyakarta. Skripsi. Universitas Yogyakarta. Yogyakarta

Garrison, Ray. H., Noreen, Eric W. 2006. Akuntansi Manajerial. Edisi Kesebelas. Buku Satu. Salemba Empat. Jakarta.

Halim, Abdul., Supomo, Bambang. 2005. Akuntansi Manajemen. Edisi Pertama. BPFE. Yogyakarta.

Harahap., Sofyan, Syafri. 2004. Analisis Krisis atas Laporan Keuangan. Rajawali Pers. Jakarta

Horngren., Datar., Foster. 2008. Akuntansi Biaya : Penekanan Manajerial. Edisi Kesebelas. Buku Satu. Indeks. Jakarta.

Khasanah, Tati Uswatun. 2007. Analisis Break Event Point. Skripsi. Universitas Yogyakarta. Yogyakarta

Kuncoro, Mudrajad. 2009. Metode Riset untuk Bisnis dan Ekonomi. Edisi 3. Erlangga. Jakarta.

Mulyadi. 2012. Akuntansi Biaya. Edisi kelima. Cetakan Kesebelas. Unit Penerbit dan Percetakan Sekolah Tinggi Ilmu Manajemen YKPN. Jogjakarta.

Zone,Franky.2009. Analisis Break Event Point. Blogspot. Jakarta

http://frenkymay.blogspot.com/2011/06/analisis-break-even-point.html . Juni 2011 